Chapter 10

\title{
pH-Sensitive Nanocrystals of Carbonate Apatite- a Powerful and Versatile Tool for Efficient Delivery of Genetic Materials to Mammalian Cells
}

\author{
Ezharul Hoque Chowdhury \\ Additional information is available at the end of the chapter \\ http://dx.doi.org/10.5772/ 53107
}

\section{Introduction}

Delivery of a functional DNA to mammalian cells is an attractive approach for genetic manipulation of the cells in biomedical research as well as in gene therapy for treating critical human diseases. Following delivery to the cytoplasm, a foreign gene enters the nucleus and is transcribed to the corresponding mRNA, which is subsequently transported to the cytoplasm for translation into a specific protein. However, a gene-silencing element, such as an antisense onligonucleotide or a small interfering RNA blocks the transcription of a target mRNA. Thus, nucleic acid delivery has been an essential tool either to turn on or off the expression of a particular gene in basic research laboratories.

Intensive research in the last three decades led to the development of a number of viral and non-viral vectors. However, an ideal vector in terms of safety and efficacy is still lacking. Synthetic non-viral vectors, such as cationic polymers, lipids and peptides, are relatively safe, but extremely inefficient. On the other hand, viral systems are by far the most effective means of DNA delivery to mammalian cells, but some major limitations including toxicity, immunogenicity, restricted targeting of specific cell types, restricted DNA carrying capacity, production and packaging problems, recombination and high cost, limit their successful applications in basic research and clinical medicine. The effectiveness of a viral particle is the result of its highly evolved and specialized structure basically composed of a protein coat surrounding a nucleic acid core. Such a highly organized structure can prevent viral particles from unwanted interactions with serum components, while promoting subsequent internalization by cells, escape from endosomes, and release of genetic material from the particle either before or after entering the nucleus. Development of a non-viral approach having the beneficial virus-like 
properties and lacking the disadvantageous aspects would emerge as the most attractive one for implementation in research laboratories and gene therapy.

A major barrier to the non-viral delivery is low uptake of DNA across the plasma membrane of a cell owing to the inappropriate and ineffective interactions of the DNA delivery vehicle with the cell membrane. Negatively charged DNA molecules are usually condensed with cationic reagents to allow formation of the complexes carrying net positive charges. The resulting complexes can interact electrostatically with anionic heparan sulfate proteoglycans (syndecans) on cell surface and reach the cytoplasmic side in the form of endosomes through endocytosis [1]. The extremely low $\mathrm{pH}$ and enzymes within the late endosomes usually bring about degradation of entrapped DNA and associated complexes. Finally, DNA that survives both endocytic processing and cytoplasmic nucleases must dissociate from the condensed complexes either before or after nuclear translocation through nuclear pore or during cell division.

Many therapeutic applications demand a vehicle with capability of delivering transgene(s) to a selective cell type in order to increase the expression efficacy and alleviate any side effect. A common strategy in non-viral case involves attachment of a targeting moiety onto a polycation (lipid or polymer) backbone which finally condenses the DNA through ionic interactions. Targeting moiety can enable the resulting DNA carrier to bind to a receptor, lectin, antigen or cell-adhesion molecule on plasma membrane prior to internalization via endocytosis or phagocytosis. Polylysine, the first backbone used for gene delivery has been conjugated to a diverse set of cell-specific ligands, such as asialoorosomucoid [2], transferrin [3], epidermal growth factor (EGF) [4], mannose [5], fibroblast growth factor (FGF) [6] and antibodies [7] for targeting, respectively, hepatocytes via asialoglycoprotein receptors, transferrin receptor-positive cells, EGF receptor-carrying cells, macrophages through membranelectins, FGF receptor-bearing cells and lymphocytes via surface-bound antigens. In the similar fashions, polymers like polyethylenimine and liposomes have been coupled to other cell surface receptor-specific ligands in addition to those described above, such as integrin-binding peptide conjugated onto PEI to target integrins on cell surfaces [8] and vitamin folate conjugated onto liposomes through a polyethylene spacer to target folate receptor-bearing cells [9].

Cell adhesion molecules (integrin, syndecan, cadherin, selectin) which are a diverse group of cell surface proteins mediating interactions between cells, and between cells and the extracellular matrix, are valuable targets for precise gene delivery to haematopoietic cells, airway epithelial cells, tumor cells and vascular endothelial cells using synthetically designed non-viral vectors [10].

Recently, we have reported on the development of a safe, efficient nano-carrier system of carbonate apatite which can assist both intracellular delivery and release of DNA leading to very high level of trans-gene expression in cancer and primary cells [11-13]. We have also revealed a new approach of organic-inorganic hybrid carrier devised by complexing fibronectin and E-cadherin-Fc chimera electrostatically with nano-particles of carbonate apatite [14, 15]. Specific recognition to cell surface integrin and E-cadherin molecules through double ligand-coated nano-particles, resulted in synergistic acceleration of transgene delivery and consequential expression into embryonic stem cells. Instead of simultaneous mixing of DNA and cell-adhesive molecules in particle-preparation medium and subsequent incubation, step- 
wise addition and incubation of DNA and the protein molecules, results in improved DNA loading and decreased particle diameter with ability of recognizing stem cell surface for more efficient transgene delivery. Activation of PKC which might up-regulate both integrin and Ecadherin, enhances transgene expression in mouse embryonic carcinoma cells.

\section{Materials and Methods}

\subsection{Reagents}

Plasmids, pGL3 (Promega) containing a luciferase gene under SV40 promoter and pEGFPN2 (CLONTECH Laboratories, Inc.) having a green fluorescence protein gene under CMV promoter were propagated in the bacterial strain XL-1 Blue and purified by QIAGEN plasmid kits. Lipofectamine 2000 and DMEM were purchased from Invitrogen and Gibco BRL, respectively. Fibronectin was bought from Sigma and expression as well as purification of Ecad-Fc fusion proteins was done according to the previously described report [16].

\subsection{Cell Culture}

HeLa cells were cultured in $75-\mathrm{cm}^{2}$ flasks in Dulbecco's modified Eagle's medium (DMEM, Gibco BRL) supplemented with $10 \%$ fetal bovine serum (FBS), $50 \mu \mathrm{g}$ penicillin $\mathrm{ml}^{-1}, 50 \mu \mathrm{g}$ streptomycin $\mathrm{ml}^{-1}$ and $100 \mu \mathrm{g}$ neomycin $\mathrm{ml}^{-1}$ at $37^{\circ} \mathrm{C}$ in a humidified $5 \% \mathrm{CO}_{2}$-containing atmosphere. F9, a mouse teratocarcinoma stem cell line and EB3, a mouse embryonic stem cell line were cultured in gelatin-coated $25-\mathrm{cm}^{2}$ flasks. F9 cells were maintained in Dulbecco's modified Eagle's medium (DMEM, Gibco BRL) supplemented with 10\% fetal bovine serum (FBS) at $37^{\circ} \mathrm{C}$ in a humidified $5 \% \mathrm{CO}_{2}$-containing atmosphere. Feeder-free murine ES cells were maintained in KNOCKOUT-DMEM (Invitrogen), supplemented with $1 \mathrm{mM} \mathrm{L-glutamine,} 1 \%$ nonessential amino acids (Invitrogen), $0.1 \mathrm{mM} \beta$-mercaptoethanol (Sigma Chemical), 10\% FBS and 1,000 units/ml leukemia inhibitory factor (LIF) (Chemicon). All media contained $50 \mu \mathrm{g} / \mathrm{ml}$ penicillin, $50 \mu \mathrm{g} / \mathrm{ml}$ streptomycin, and $100 \mu \mathrm{g} / \mathrm{ml}$ neomycin.

\subsection{Transfection of cells}

Cells from the exponentially growth phase were seeded at 50,000 cells per well into 24-well plates the day before transfection. 3 to $6 \mu \mathrm{l}$ of $1 \mathrm{M} \mathrm{CaCl}_{2}$ was mixed with $2 \mu \mathrm{g}$ of plasmid DNA in $1 \mathrm{ml}$ of fresh serum-free HCO3 - buffered ( $\mathrm{pH}$ 7.5) medium (DMEM) and incubated for 30 min at $37^{\circ} \mathrm{C}$ for complete generation of DNA/carbonate apatite particles. For generation of ECM protein-embedded carbonate apatite particles, fibronectin and E-cad-Fc proteins were added either alone or together to a final concentration of $5 \mu \mathrm{g} / \mathrm{ml}$, to $\mathrm{Ca}^{2+}$ and DNA-containing DMEM followed by incubation at $37^{\circ} \mathrm{C}$ for $30 \mathrm{~min}$. Medium with generated ECM protein-associated or non-associated, DNA-containing particles was added with 10\% FBS to the rinsed cells. After $4 \mathrm{hr}$ incubation, the medium was replaced with serum supplemented medium and the cells were cultured for 1 day. Luciferase gene expression was monitored by using a commercial kit (Promega) and photon counting (TD-20/20 Luminometer, USA). Each transfection experiment was done in triplicate and transfection efficiency was expressed as mean light units per mg of cell protein. For lipofectamine-mediated transfection, protocol provided by Invitro- 
gen was followed in a 24-well plate. Cells were incubated with DNA/lipofactamine complexes in serum-free media for $4 \mathrm{hr}$ and like above, grown for 1 day after replacement with fresh serum media.

For transfection with calcium phosphate-DNA co-precipitation, briefly, $12 \mu \mathrm{g}$ of plasmid DNA was added to $300 \mu \mathrm{l}$ of a solution containing $250 \mathrm{mM} \mathrm{CaCl}_{2}$. This solution was added to $300 \mu \mathrm{l}$ of a $2 \times \mathrm{HBS}\left(50 \mathrm{mM}\right.$ Hepes, $\left.140 \mathrm{mM} \mathrm{NaCl}, 1.5 \mathrm{mM} \mathrm{Na}_{2} \mathrm{HPO}_{4} .2 \mathrm{H}_{2} \mathrm{O}, \mathrm{pH} 7.05\right)$ and mixed rapidly by gentle pipetting twice. The DNA/CaPi mixture was incubated at room temperature for the period of time indicated. After addition of $100 \mu \mathrm{l}$ of the incubated mixture drop-wise to $1 \mathrm{ml}$ serum supplemented media of each well, cells were incubated for $4 \mathrm{hr}$ and like above, after replacement with fresh serum media, grown for 1 day.

\subsection{MTT assay}

HeLa cells were transfected and cultured for 1 day as described above. $30 \mu \mathrm{l}$ of MTT solution $(5 \mathrm{mg} / \mathrm{ml})$ was added to each well and incubated for $4 \mathrm{hrs} .0 .5 \mathrm{ml}$ of DMSO was added after removal of media. After dissolving crystals and incubating for $5 \mathrm{~min}$ at $37^{\circ} \mathrm{C}$, absorbance was measured in a microplate reader at $570 \mathrm{~nm}$ with a reference wavelength of $630 \mathrm{~nm}$.

\subsection{Chemical analysis}

Following generation of carbonate apatite as described above, using $6 \mathrm{mM} \mathrm{Ca}^{2+}$ and no DNA, precipitated particles were lyophilized after centrifugation and washing with distilled deionized water. Other apatite particles generated as described above, were also similarly lyphilized. Calcium and phosphorus contents were determined usingSPS1500VRAtomic Absorption Spectrophotometer. Carbon and fluorine were estimated by CHNS-932 (Leco, USA) and SXelements micro analyser, YS-10 (Yanaco, Japan), respectively.

\subsection{Infrared spectroscopy}

Fourier transform-infrared spectroscopy of apatite particles prepared as described above, was performed using FT/IR-230, JASCO. The samples were ground in a mortar and approximately $1 \mathrm{mg}$ was thoroughly mixed with $300 \mathrm{mg}$ of ground spectroscopic grade KBr. Transparent pellets were prepared in a $\mathrm{KBr}$ die with an applied load of $8000 \mathrm{~kg}$, under a vacuum of 0.5 torr.

\subsection{X-ray diffraction}

The x-ray diffraction powder reflections of the particles prepared as described above, were recorded using M18XHF-SRA diffractometer system.

\subsection{Particle size measurements}

For visualization by a scanning electron microscope (SEM), a drop of DNA-carbonate apatite suspension prepared according to the instructions in transfection protocol, was added to a carbon-coated SEM stage and dried, followed by observation by a high resolution SEM (S-800, Hitachi, Japan). Dynamic light scattering (DLS) measurement for particle suspension was 
carried out with a Super-dynamic Light Scattering Spectrophotometer, ‘Photal' (Otsuka Electronics) at $75 \mathrm{~mW}$ Ar laser.

\subsection{Confocal laser scanning microscopy}

pGL3 vector was labeled with PI at a PI/DNA ratio of 1:1 and particles generated with this labeled plasmid (described in transfection protocol), were incubated with HeLa cells for 6 hours. Acidic compartments were labeled with $5 \mu \mathrm{M}$ LysoSensor, according to the instructions provided by Molecular Probes, and membrane-bound precipitates were removed by 5 mM EDTA in PBS before observation by LEICA TCS-NT.

\subsection{SDS-PAGE and Western blotting}

Following generation of carbonate apatite as described above using $3 \mathrm{mM} \mathrm{Ca}^{2+}$ and required amount of fibronectin or E-cad-Fc chimera and no DNA and centrifugation at $15000 \mathrm{rpm}$ for $5 \mathrm{~min}$ at $4^{\circ} \mathrm{C}$, precipitated particles were washed with water with several centrifugation steps to remove unbound proteins and dissolved with $50 \mathrm{mM}$ EDTA in PBS for subsequent analysis by 7.5\% SDS-PAGE in reducing condition. In order to see particle-bound fibronectin, after SDS-PAGE, the gel was stained with Coumassie blue, washed and dried. For detection of particle-associated E-cad-Fc, proteins after being run by SDS-PAGE were transferred to PVDF membrane (Immobilon, Millipore) and $80 \mathrm{~mA}$ current was applied for $90 \mathrm{~min}$ to complete transfer of the proteins. The PVDF membrane was washed with PBS (-)-containing $0.1 \%$ Tween 20 and then blocked for $1 \mathrm{hr}$ at room temperature by "Blocking One" (Nacalai Tesque, Japan). The membrane was incubated with horseradish peroxidase (HRP)-conjugated antimouse IgG for $1 \mathrm{hr}$ and washed with PBS-T three to four times to completely remove nonspecific interactions. Enhanced chemiluminescence system (Amersham Bioscience) was used for visualization.

\subsection{DNA labelling, fluorescence microscopy and flow cytometry}

Plasmid DNA was labelled non-covalently with propidium iodide (PI) using 1:1 weight ratio of DNA to PI in the particle preparation medium. Labelled DNA inside the cells was observed by a fluorescence microscope (Olympus-IX71), following $4 \mathrm{hr}$ incubation of differentially formulated particle suspensions with F9 cells and removing extracellularly bound particles by $5 \mathrm{mM}$ EDTA in PBS. For flow cytometric analysis using FACS Calibur (Becton, Dickinson and Company), 1 day after transfection with pEGFP plasmid DNA, F9 cells were collected in a sorter buffer following treatment with trypsin-EDTA and repeated centrifugation and washing of the resulting cell pellet with PBS (-) (2 times).

\section{Results and Discussion}

\subsection{Generation of carbonate apatite particles}

Addition of only $3 \mathrm{mM} \mathrm{Ca}{ }^{2+}$ to the $\mathrm{HCO}_{3}{ }^{-}$- buffered cell culture medium (DMEM or Willium $\mathrm{E}, \mathrm{pH} 7.5$ ) and incubation at $37^{\circ} \mathrm{C}$ for $30 \mathrm{~min}$, resulted in microscopically visible parti- 
cles. Generation of these particles only in $\mathrm{HCO}_{3}{ }^{-}$-, but not in Hepes-buffered media or solution ( $\mathrm{pH} 7.5$ ) containing the same amount of exogenous $\mathrm{Ca}^{2+}$ and phosphate $(0.9 \mathrm{mM})$, indicates the possible involvement of carbonate along with phosphate and $\mathrm{Ca}^{2+}$ in particle formation. Elemental analysis proved the existence of $\mathrm{C}(3 \%), \mathrm{P}(17 \%)$ and $\mathrm{Ca}^{2+}(32 \%)$ and FT-IR spectra (Fig. 1a) identified carbonate, as evident from the peaks between 1410 and $1540 \mathrm{~cm}^{-1}$ and at approximately $880 \mathrm{~cm}^{-1}$, along with phosphate in the particles, as shown by the peaks at $1000-1100 \mathrm{~cm}^{-1}$ and $550-650 \mathrm{~cm}^{-1}$. X-ray diffraction patterns (Fig. 1b) indicated less crystalline nature, represented by broad diffraction peaks of the particles, compared to that of hydroxyaptite (Fig. 1c) - an intrinsic property of carbonate apatite [12].
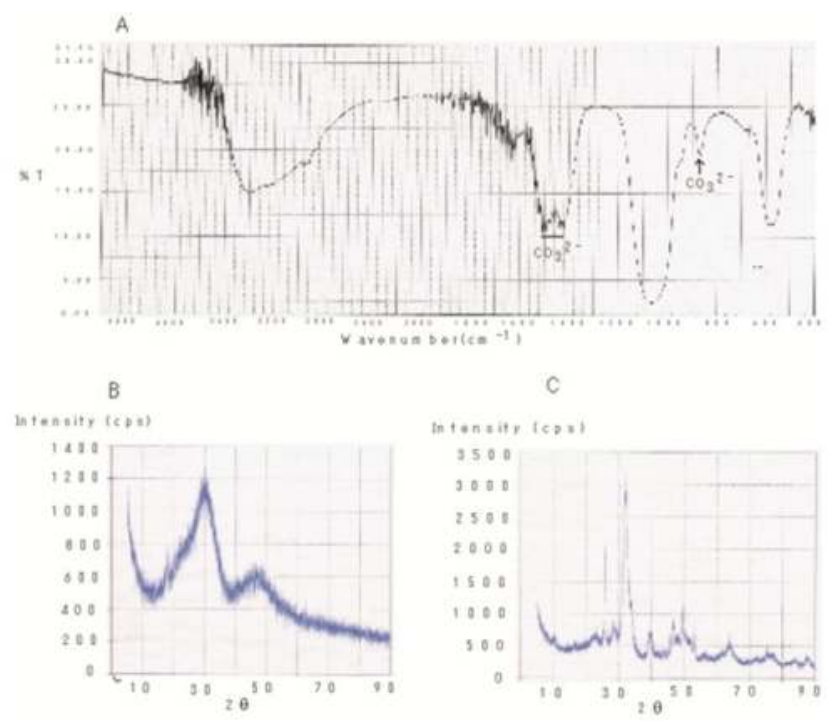

Figure 1. Infrared spectra of generated carbonate apatite (A) and X-ray diffraction patterns of carbonate apatite (B) and hydroxyapatite $(C)$.

\subsection{Influences of $\mathrm{pH}$ and temperature on generation of effective particles of carbonate apatite}

We have investigated a long range of $\mathrm{pH}$ (7.0 to 7.9) of the $\mathrm{HCO}_{3}{ }^{-}$-buffered medium as well as incubation temperatures $\left(25^{\circ} \mathrm{C}\right.$ to $\left.65^{\circ} \mathrm{C}\right)$ in order to make particles by exogenously added $\mathrm{Ca}^{2+}$ and subsequently transfect HeLa cells using the generated particles. Interestingly, the optimal $\mathrm{Ca}^{2+}$ concentrations required for generation of effective number of DNA/carbonate apatite particles leading to the high transfection efficiency, were inversely related to the $\mathrm{pHs}$ of the media (Fig. 2-a) and the incubation temperatures (Fig. 2-b). Thus, while $4 \mathrm{mM} \mathrm{Ca}^{2+}$ was sufficient to induce particle formation at $\mathrm{pH} 7.4$ by incubating the $\mathrm{Ca}^{2+}$-supplemented buffered medium for $30 \mathrm{~min}$ at $37^{\circ} \mathrm{C}$, only $1 \mathrm{mM}^{2+}$ was enough to stimulate particle generation to the similar level at $\mathrm{pH}$ 7.9. Like $\mathrm{pH}$, incubation temperatures have also profound and 
sensitive effects on particle formulation and subsequent trans-gene delivery. Thus, at the incubation temperature of $37^{\circ} \mathrm{C}, 3 \mathrm{mM} \mathrm{Ca}^{2+}$ was able to induce the proper "supersaturation" whereas at $65^{\circ} \mathrm{C}$, only $1 \mathrm{mM} \mathrm{Ca}{ }^{2+}$ could stimulate "supersaturation" development to a similar extent - a prior need for generation of the particles. The decline below the high efficiency level of transfection was due to the formation of too few particles (microscopically observed) since increase in $\mathrm{pH}$ or temperature contributed to the development of "supersaturation" by increasing the ionization of phosphate and carbonate in the solution. The new system of particle synthesis is, therefore, very flexible since it allows us to make particles at a wide range of $\mathrm{pH}$ and temperatures. The analysis also indicates that induction of "supersaturation" as required for particle formation, can be delicately controlled by manipulating the parameters.
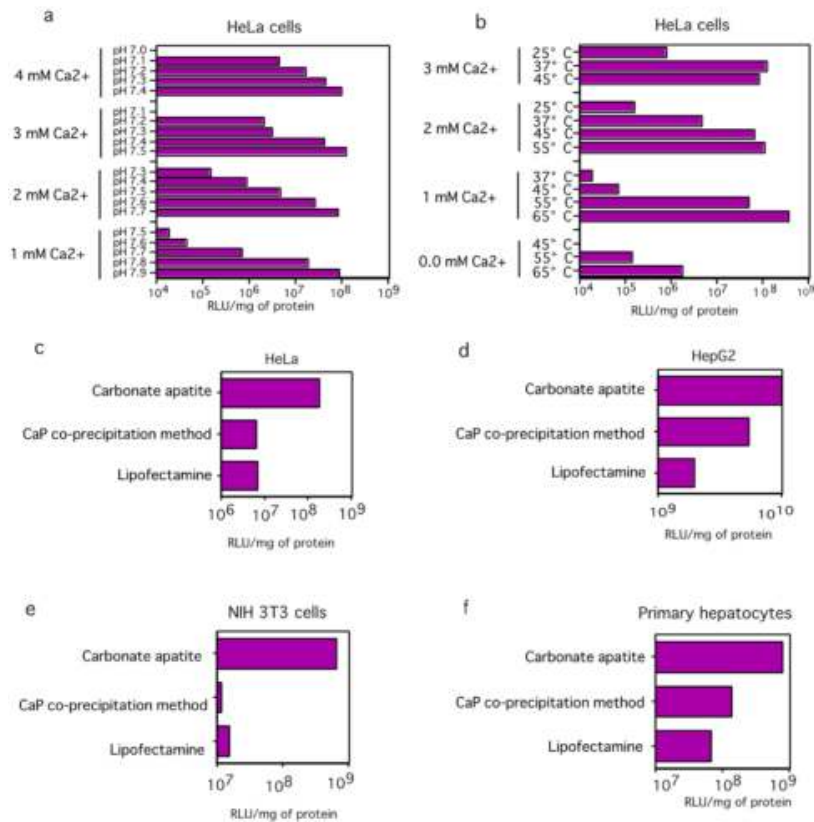

Figure 2. Regulation of trans-gene delivery and expression facilitated by carbonate apatite particles. Regulation of trans-gene expression by the nanoparticles of carbonate apatite generated at a wide range of $\mathrm{pH}$ and temperature. DNA/carbonate apatite particles were generated by addition of 1 to $4 \mathrm{mM} \mathrm{Ca}^{2+}$ and $2 \mu \mathrm{g}$ plasmid DNA to $1 \mathrm{ml} \mathrm{HCO}_{3}-$ (40 mM)-buffered DMEM medium with a pH range from 7.0 to 7.9, followed by incubation for 30 min either at $37^{\circ} \mathrm{C}$ (a) or at $25^{\circ} \mathrm{C}$ to $65^{\circ} \mathrm{C}$ (b). Transfection of HeLa cells, HepG2, NIH3T3 and primary hepatocytes was performed in the same manner as mentioned in 'Materials and methods' section.

\subsection{Tranfection efficiency and cell viability assessment}

To evaluate the role of carbonate apatite as a powerful carrier of genetic material, we compared transfection efficiency of different techniques including two frequently used ones$\mathrm{CaP}$ co-precipitation method and lipofection. In HeLa cell, for example, luciferase 
expression level for carbonate apatite-mediated transfection was over 25-fold higher than for lipofection and CaP co-precipitation method (Fig. 2c). Nano gram level of DNA was even sufficient for efficient transgene expression (Fig. 2c). Transfection efficiency was also significantly high in HepG2 (Fig. 2d), NIH 3T3 cells (Fig. 2e) and mouse primary hepatocytes (Fig. 2f). We performed MTT assay in HeLa cells (not shown here) to clarify that high transfection efficiency was accompanied by high viability of the cells [12].

\subsection{Estimation of particle sizes and cellular uptake of particle-associated plasmid DNA}

To explore why carbonate apatite is so efficient as a vector for gene delivery, we investigated two basic properties of carbonate apatite [12]. Carbonate, when present in the apatite structure, limits the size of the growing apatite crystals and increases the dissolution rate [12]. We carried out scanning electron microscopic observation of generated carbonate apatite (Fig. 3A) which revealed reduced growth of the crystals, most of which had diameters of 50 to $300 \mathrm{~nm}$. We verified this size limiting effect of carbonate by observing cellular uptake of the PI (propidium iodide)-labeled plasmid DNA adsorbed to the apatites, since large particles are phagocytosed less efficiently than small ones [12]. DNA was carried into the cells by carbonate apatite (Fig. 3B-c) at least 10 times more efficiently than hydroxyapatite, generated by $1 \mathrm{~min}$ incubation (Fig. 3B-d). Longer period (30 min) incubation resulted in large hydroxyapatite particles [12], showing significantly reduced transfection efficiency [12] (Fig. 2A) due to extremely low cellular uptake of DNA [12]. Our findings, therefore, clearly suggest that carbonate apatite is superior over hydroxyapatite for its intrinsic property of preventing crystal growth, leading to high efficiency cellular uptake of DNA.
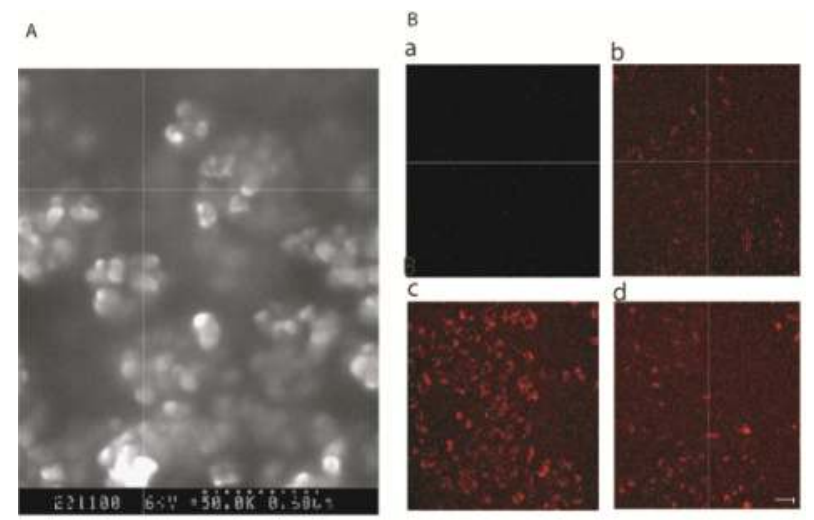

Figure 3. A, scanning electron microscopy, showing limited growth of generated carbonate apatite cryatals. Scale bar, $600 \mathrm{~nm}$. B, cellular uptake of PI-labeled plasmid DNA associated with carbonate apatite and hydroxyapatite. a, no uptake of DNA (control), since endocytosis was blocked by energy depletion (50 mM 2-deoxy glucose and $1 \mathrm{mM}$ Naazide). DNA/carbonate apatite particles were prepared in $1 \mathrm{ml}$ serum-free media (described in legend to Fig. 3) using $6 \mathrm{mM} \mathrm{Ca}^{2+}$ and $2 \mu \mathrm{g}$ DNA. $40 \mathrm{ng}$ (b) and $200 \mathrm{ng}$ (c) of DNA in $20 \mu \mathrm{l}$ and $100 \mu \mathrm{l}$ of $1 \mathrm{ml}$ suspension respectively, were allowed for cellular uptake for $4 \mathrm{hr}$. d, $2 \mu \mathrm{g}$ of DNA adsorbed to hydroxyapatite (described in experimental protocol) was allowed for uptake for the same period of time. Bar indicates $50 \mu \mathrm{M}$. 


\subsection{Endosomal escape of plasmid DNA carried by nanoparticles}

To evaluate the role of endosomal escape of DNA in transgene expression, following endocytosis of PI-labeled plasmid DNA, we labeled endosomes with LysoSensor (a fluorescence probe for endosomes). Following 6 hr of DNA uptake by cells, a significant portion of DNA (red colour) appeared to be released from endosomes (green colour) after colocalization of plasmid DNA with endosomes (Fig. 4).
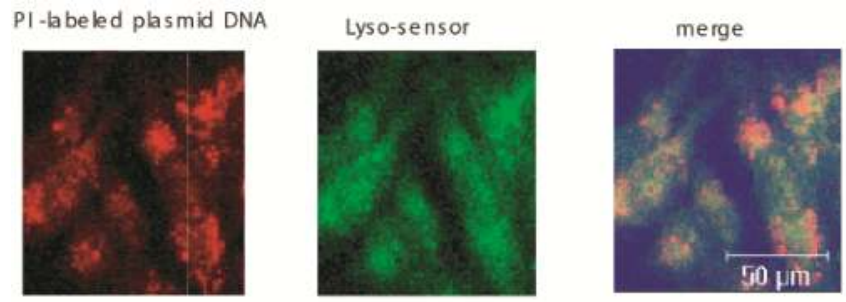

Figure 4. Endosomal escape of endocytosed PI-labeled DNA, as evident after colocalization with a fluorescence probe (Lyso-Sensor) for endosomes.

\subsection{Relationship of endosomal $\mathrm{pH}$ and crystalline properties of particles affecting transfection}

Treatment with bafilomycin A1, a specific inhibitor of v-ATPase (a proton pump for acidification of endocytic vesicles) resulted in drastic reduction of transfection efficiency in HeLa cells (Fig. 5A), which indicated that acidic environment might be necessary for solubilization of carbonate apatite to release DNA from the apatite. To establish this notion, we generated fluoridated carbonate apatite to see the effect of solubility of the particles on transfection efficiency, since incorporation of fluoride reduces the solubility of the apatite [12]. Surprisingly, transfection efficiency was reduced gradually to a significant extent (100 fold) with increasing fluoride level in carbonate apatite (Fig. 5B).
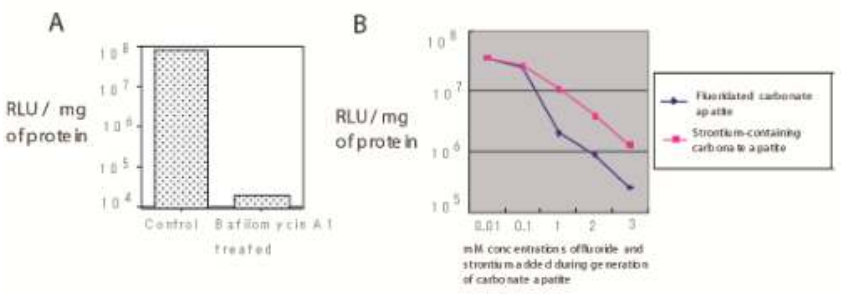

Figure 5. A, Effect of bafilomycin A1 (an inhibitor of v-ATPase) on transfection. HeLa cells were incubated with DNA/ carbonate apatite particles and $200 \mathrm{nM}$ bafilomycin A1 for $6 \mathrm{hr}$. After washing with $5 \mathrm{mM}$ EDTA in PBS, cells were grown for 1 day and luciferase expression was detected. B, Changes in luciferase expression for increasing concentrations of $\mathrm{F}^{-}(0.01$ to $3 \mathrm{mM})$ and strontium ( 0.01 to $\left.3 \mathrm{mM}\right)$ added during generation of DNA/carbonate apatite particles. 
To establish a relationship between transfection efficiency and dissolution rates of the apatites, turbidity $(320 \mathrm{~nm})$ measurement was done as an indicator of their solubilization, following an acid load in solution of generated apatites. Carbonate apatite generated in presence of increasing concentrations of $\mathrm{NaF}$, showed gradual decrease in dissolution rates, as evident from changes in turbidity, following adjustment of $\mathrm{pH}$ from 7.5 to 7.0 with $1 \mathrm{~N}$ $\mathrm{HCl}$ (Fig. $6 \mathrm{~A}, \mathrm{~B}$ ), which is consistent with gradually reduced transfection efficiency of fluoridated carbonate apatites (Fig. $5 \mathrm{~B}$ ). With decreasing $\mathrm{pH}$ from 7.0 to 6.8, carbonate apatite was completely solubilized within $1 \mathrm{~min}$, whereas fluoridated carbonate apatite was partially dissolved (Fig. 6 B).

To examine whether dissolution rates of apatites are correlated with their degree of crystallization, we studied x-ray diffraction of the apatites (Fig. 7), which clearly indicates that apatite with higher degree of crystallization, had lower solubility (Fig. 6A). In other words, apatites with higher crystallinity (Fig. 7) showed lower transfection efficiency (Fig. 5 B). The gradual increase in crystallinity owing to increased level of incorporated fluoride in carbonate apatite (Fig. 7) resulted in gradual decrease in transfection efficiency (Fig. 5B).
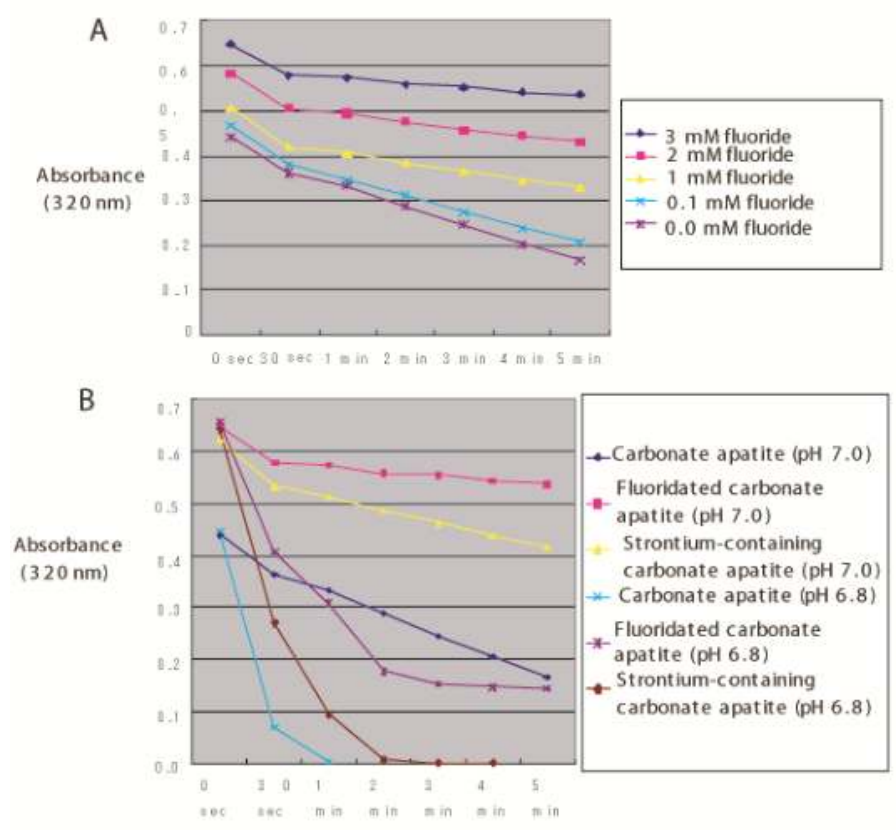

Figure 6. A, Dissolution rates (at $\mathrm{pH}$ 7.0) of fluoridated carbonate apatites prepared by addition of 0-3 mM F- during generation of carbonate apatite at $\mathrm{pH} 7.5$ (described in experimental protocol), were studied by turbidity measurement at $320 \mathrm{~nm}$ of apatite suspensions just after being adjusted to the $\mathrm{pH} 7.0$ with $1 \mathrm{~N} \mathrm{HCl}$. B, Dissolution rates of carbonate apatite, fluoridated carbonate apatite and strontium-containing carbonate apatite at pHs of 7.0 and 6.8. 

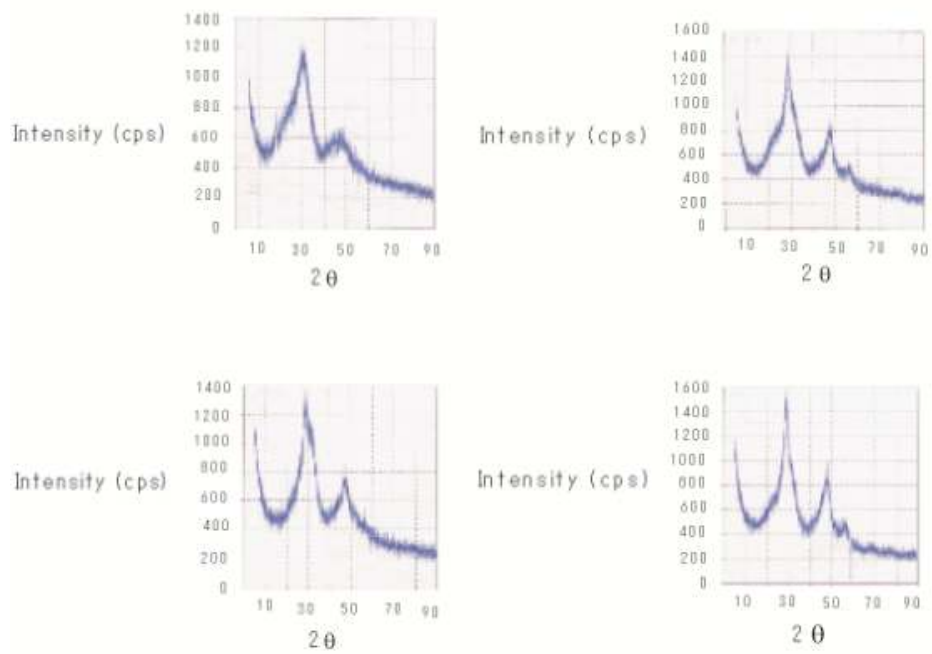

Figure 7. X-ray diffraction patterns of carbonate apatite $(A)$ and fluoridated carbonate apatites, containing $0.65 \%$ (B), $1.43 \%(C)$ and $2.5 \%(D)$. Carbonate apatite was generated by addition of $6 \mathrm{mM} \mathrm{Ca}^{2+}$ and fluoridated carbonate apatites by addition of $1 \mathrm{mM}(\mathrm{B}), 2 \mathrm{mM}$ (C) and $3 \mathrm{mM}$ (D) $\mathrm{NaF}$ along with $6 \mathrm{mM} \mathrm{Ca}{ }^{2+}$ to $\mathrm{HCO}_{3}{ }^{-}$-buffered medium $(\mathrm{pH} 7.5)$, followed by incubation at $37^{\circ} \mathrm{C}$

To establish that decreased transfection efficiency was only due to decreased solubility of fluoridated carbonate apatite, but not by any other fluoride-mediated effects, we examined the effects of strontium which, when incorporated into carbonate apatite, is known to improve the crystallinity and reduce the solubility of the apatite, but to a lesser extent than fluoride [12]. As expected, addition of strontium chloride during preparation of carbonate apatite reduced its dissolution rate but to a level less than that observed for fluoride (Fig 6B). Moreover, transfection efficiency was gradually decreased with increasing concentrations of strontium chloride during generation of DNA/carbonate apatite particles (Fig. 5B). Taken together, our findings suggest that intracellular release of DNA through dissolution of apatite should play a major role in carbonate apatite-mediated transfection.

\subsection{Immobilization of cell-adhesive molecules on nano-particle surface}

Since embryonic stem cells produce substantial amount of fibronectin-specific integrins as well as E-cadherin as transmembrane proteins [17], we hypothesized that if the nano-particles of carbonate apatite could be complexed with fibronectin and E-cadherin, either individually or together, they might recognize in the immobilized state the corresponding receptors on cell surface in order to facilitate quick internalization of the composite particles across the plasma membrane through endocytosis. These nano-apatite particles possess anion- and cation-binding domains which enable them to bind to both acidic and basic amino acids of protein molecules $[18,19]$. On the other hand, fibronectin as well as E-cadherin are rich in acidic amino acid residues $[19,20]$ which make them excellent candidates for pos- 
sible binding with the apatite particles. We have examined whether these "cell adhesive molecules" could, in deed, bind to the particles, by SDS-PAGE and Western blot analysis, following generation of apatite-protein composites and decomplexation through EDTAmediated particle dissolution. Whereas binding affinity of the particles for fibronectin was relatively lower requiring higher amount of initially added fibronectin as observed by SDSPAGE, almost all E-cad-Fc was found to be associated with the particles as verified by Western blot analysis (Fig 8). Very high affinity for E-cadherin could be interpreted by the previous report that E-cadhein has many exposed acidic residues in several loop structures responsible for binding divalent cation $\mathrm{Ca}^{2+}[20]$.
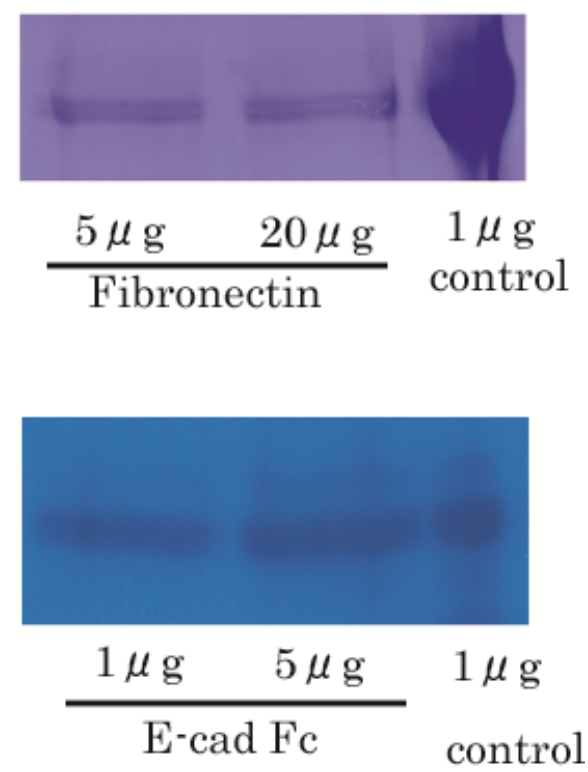

Figure 8. Analysis of the binding of cell-adhesive proteins to nano-particles. Particles were prepared by addition of 3 $\mu \mathrm{l}$ of $1 \mathrm{M} \mathrm{CaCl}_{2}$ and 5 to $20 \mu \mathrm{g}$ of fibronectin or 1 to $5 \mu \mathrm{g}$ of E-cad-Fc to $1 \mathrm{ml}$ bicarbonate-buffered DMEM and incubation for $30 \mathrm{~min}$ at $37^{\circ} \mathrm{C}$. Generated particles were centrifuged at $15000 \mathrm{rpm}$ for $5 \mathrm{~min}$ and washed 2 times with $\mathrm{H}_{2} \mathrm{O}$ to remove the unbound proteins, followed by EDTA treatment to dissolve the particles. SDS-PAGE and Western blot analysis were performed in order to see, respectively, particle-associated fibronectin (A) or E-cad-Fc (B).

\subsection{Enhanced cellular uptake of DNA by immobilized cell-adhesive molecules}

In order to explore whether apatite particles functionalized with fibronectin and E-cad-Fc can facilitate enhanced delivery of apatite-associated plasmid DNA across the plasma membrane, we examined cellular uptake of the DNA labeled with propidium iodide (PI) [19], following $4 \mathrm{hr}$ incubation of F9 cells with various particle formulations. As shown in Fig. 9, 
while with only apatite particles, delivery of PI-labeled DNA into the cells was extremely low, complexation of the particles with either fibronectin or E-cad-Fc resulted in significantly improved DNA delivery, suggesting that immobilized fibonectin or E-cad-Fc retained their functionalities in order to recognize specific cell surface integrin or E-cadherin, respectively for enabling subsequent internalization of the whole particle composite through endocytosis $[19,21]$. Moreover, the apatite particles when complexed with both fibronectin and E-cad-Fc, demonstrated more pronounced DNA delivering activity compared to the particles embedded with either fibronectin or E-cad-Fc, indicating a synergistic effect of the multifunctional particles on endocytosis through simultaneous recognition of extracellular domains of specific integrin as well as E-cadherin molecules.

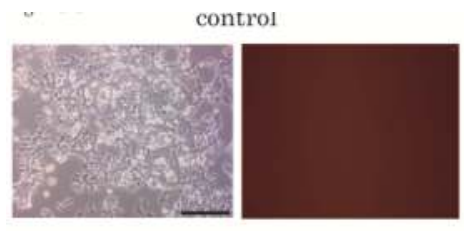

fibronectin+apatite
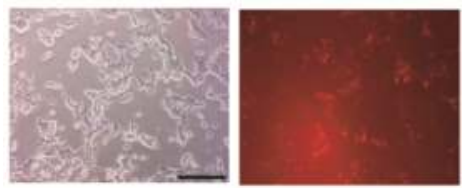

fibronectin+E-cad-Fc+apatite

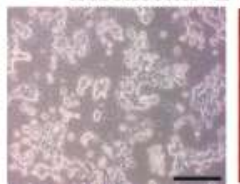

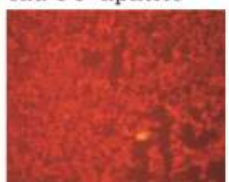

only apatite

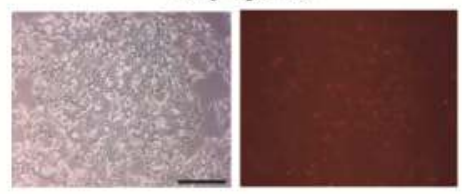

E-cad-Fc+apatite
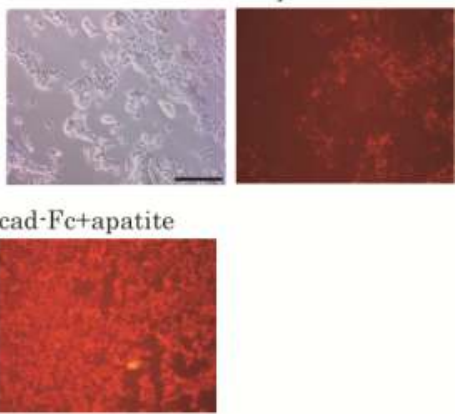

Figure 9. Effects of particle-immobilized proteins on cellular internalization of plasmid DNA. Particles were prepared by addition of $3 \mu \mathrm{l}$ of $1 \mathrm{M} \mathrm{CaCl}_{2}, 2 \mu \mathrm{g}$ of Pl-labelled plasmid DNA and $5 \mu \mathrm{g}$ of fibronectin and/or $5 \mu \mathrm{g}$ of E-cad-Fc to 1 $\mathrm{ml}$ bicarbonate-buffered DMEM and incubation for $30 \mathrm{~min}$ at $37^{\circ} \mathrm{C}$. F9 cells were incubated with the generated particles for $4 \mathrm{hr}$, washed with $5 \mathrm{mM}$ EDTA in PBS and visualized by a fluorescence microscope (scale bar, $50 \mu \mathrm{m}$ ).

\subsection{Quantitation and validation of trans-gene expression facilitated by cell-adhesive molecules}

Since expression of a trans-gene is the result of overcoming a number of barriers including entry into the cells, release from the particle and endosomes and finally nuclear translocation $[17,18]$, we have investigated whether improved DNA delivery as a result of integrinand E-cadherin-mediated endocytosis of composite particles (Fig. 9) contributed to the similar extent to final protein expression. Quantitative luciferase expression analysis indicated that particles complexed with fibronectin or E-cad-Fc promoted trans-gene expression 
with a value which was almost 20 times higher than that achieved for the particles only (Fig 10). A prior optimization study demonstrated that 1 to $5 \mu \mathrm{g} / \mathrm{ml}$ of fibronectin as well as Ecad-Fc conferred the best transfection efficiency and was, therefore, maintained for all subsequent experiments. Finally, synergistic activity of fibronectin and E-cad-Fc which caused huge cellular uptake of DNA (Fig. 9), further accelerated gene expression efficiency with a value almost 3 times higher than that observed for commercially available lipofectamine (Fig. 10). With increasing the total amount of initially added DNA up to $4 \mu \mathrm{g}$, a further increase in trasfection efficiency was observed (data not shown here) possibly due to the higher loading of DNA into the crystals with the consequence of more DNA getting inside the cells. The high level of expression could directly be observed by fluorescence microscopy which demonstrated many GFP-expressing F9 cells (Fig. 11). Fluorescence Activated Cell Sorting (FACS) analysis demonstrated that almost $60 \%$ cells were GFP-positive following transfection with the particles carrying, in addition to pEGFP plasmid DNA, both fibronectin and E-cad-Fc (Fig 11). MTT assay was performed in F9 cells to clarify that high transfection efficiency was not accompanied by significant toxicity of the cells (data not shown here). In order to establish that such organic-inorganic hybrid particles promote trans-gene delivery and expression through specific interactions with cell-surface molecules (integrin or E-cadherin), we added increasingly high amounts of free fibronectin to the preformed particle suspension carrying both fibronectin and E-cadherin and incubated with the cells for the same period of time ( $4 \mathrm{hr}$ ) as followed in usual transfection procedure. Transfection efficiency decreased as the concentration of free fibronectin increased from 5 to $100 \mu \mathrm{g} / \mathrm{ml}$, indicating the involvement of specific interactions between immobilized fibronectin and the corresponding specific integrin receptors (Fig 12). At a sufficiently high concentration (300 $\mu \mathrm{g} / \mathrm{ml})$, free fibronectin drastically reduced luciferase expression suggesting that high amount of fibronectin molecules not only saturate their specific integrins and block binding of immobilized fibronectin needed for particle internalization, but also shield cell-surface Ecadherin and prevent specific binding of particle surface-embedded E-cad-Fc chimera leading to very low cellular uptake of particle-associated DNA and diminished luciferase expression. Since embryonic stem cells are the final target for genetic modification in regenerative medicine, we applied the new transfection approach to mouse embryonic stem cells. As shown in Fig. 13, only apatite particles were extremely inefficient in transfecting the cells, whereas fibronectin-bound particles to some extent promoted GFP expression and fibronectin and E-cad-Fc-bound particles to a significant extent accelerated trans-gene expression, thus proposing that the synergistic effect is a universal way of accelerating trans-gene delivery and expression using inorganic nano-particle-associated cell recognizable proteins. Quantitative luciferase expression in embryonic stem cells indicated that particles complexed with fibronectin and E-cad-Fc individually, promoted trans-gene expression with efficiency approximately 9 and 7 times higher, respectively, than that achieved with the particles only (Fig. 14). However, when the particles were associated with both fibronectin and E-cadherin-Fc, a synergistic effect resulted in remarkable level of transgene expression leading to almost 40 and 28 times higher efficiency than that obtained by apatite particles and widely used lipofectamine 2000 system [14]. 


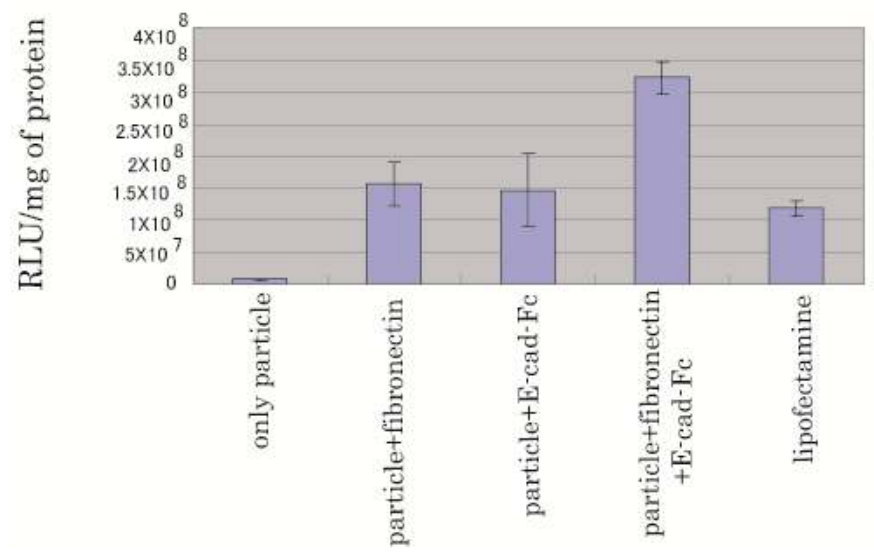

Figure 10. Comparison of luciferase expression for differentially formulated particles. Particles were prepared by addition of $3 \mu \mathrm{l}$ of $1 \mathrm{M} \mathrm{CaCl}_{2}, 2 \mu \mathrm{g}$ of luciferase plasmid DNA and $5 \mu \mathrm{g}$ of either fibronectin, E-cad-Fc or both to $1 \mathrm{ml}$ bicarbonate-buffered DMEM and incubation for $30 \mathrm{~min}$ at $37^{\circ} \mathrm{C}$. F9 cells were incubated with the generated particles for 4 hr and after replacement of particle-containing media with fresh media, further incubated for 1 day in order to quantitate luciferase expression. Transfection efficiency was normalized after estimation of total proteins in cell lysate.

\section{Only apatite particles}

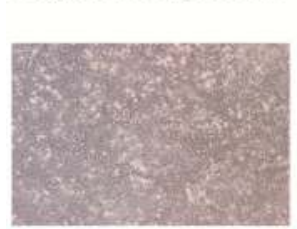

Particles with associated Fibronectin and E-cad-Fc
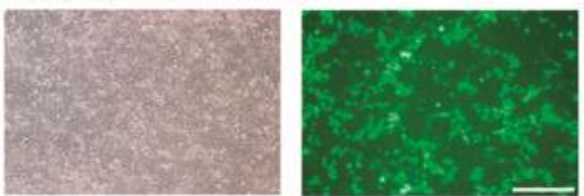

Flow cytometry
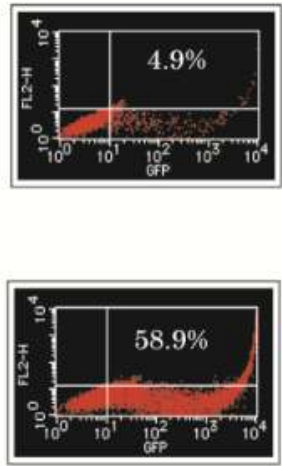

Figure 11. Comparison of GFP expression between only particles and fibronectin/E-cad-Fc-embedded-particles. Particles were prepared by addition of $3 \mu \mathrm{l}$ of $1 \mathrm{M} \mathrm{CaCl}_{2}, 2 \mu \mathrm{g}$ of pEGFP plasmid DNA and $5 \mu \mathrm{g}$ of fibronectin and $5 \mu \mathrm{g}$ of Ecad-Fc to $1 \mathrm{ml}$ bicarbonate-buffered DMEM and incubation for $30 \mathrm{~min}$ at $37^{\circ} \mathrm{C}$. F9 cells were incubated with the generated particles for $4 \mathrm{hr}$ and after replacement of particle-containing media with fresh media, further incubated for 1 day in order to both observe and quantitate GFP expression by fluorescence microscopy and flow cytometry, respectively (scale bar, $50 \mu \mathrm{m}$ ). 


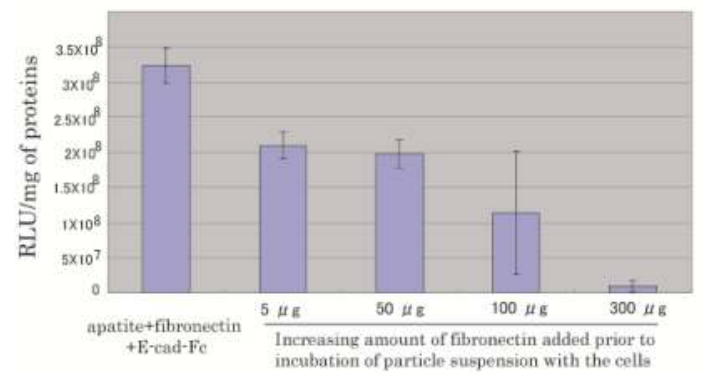

Figure 12. Blocking of integrin-mediated trans-gene delivery by excess free fibronectin. Particles were prepared by addition of $3 \mu \mathrm{l}$ of $1 \mathrm{M} \mathrm{CaCl}_{2}, 2 \mu \mathrm{g}$ of luciferase plasmid DNA and $5 \mu \mathrm{g}$ of fibronectin and $5 \mu \mathrm{g}$ of E-cad-FC to $1 \mathrm{ml}$ bicarbonate-buffered DMEM and incubation for $30 \mathrm{~min}$ at $37^{\circ} \mathrm{C}$. F9 cells were incubated with the generated particles in presence or absence of increasingly high concentrations of free fibronectin for $4 \mathrm{hr}$ and after replacement of particlecontaining media with fresh media, further incubated for 1 day in order to quantitate luciferase expression. Transfection efficiency was normalized after estimation of total proteins in cell lysate.

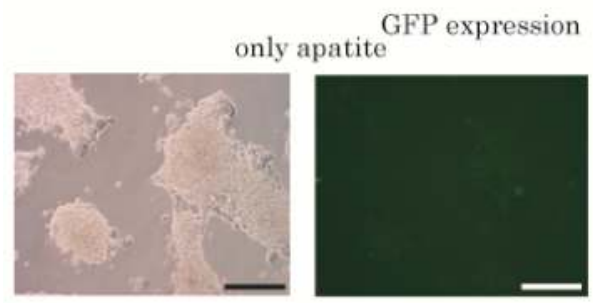

apatite+fibronectin
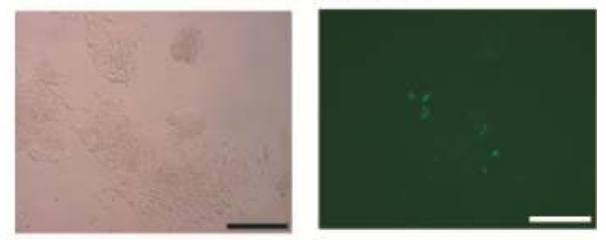

apatite+fibronectin+E-cad-Fc
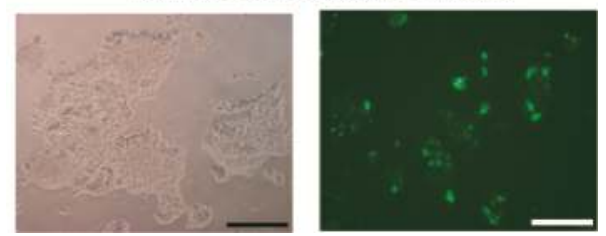

Figure 13. Enhancement of GFP expression in mouse embryonic stem cells with fibronectin/E-cad-Fc-embedded-particles. Particles were prepared by addition of $3 \mu \mathrm{l}$ of $1 \mathrm{M} \mathrm{CaCl}_{2}, 2 \mu \mathrm{g}$ of pEGFP plasmid DNA and $5 \mu \mathrm{g}$ of fibronectin and 5 $\mu \mathrm{g}$ of E-cad-Fc to $1 \mathrm{ml}$ bicarbonate-buffered DMEM and incubation for $30 \mathrm{~min}$ at $37^{\circ} \mathrm{C}$. Embryonic stem cells were incubated with the generated particles for $4 \mathrm{hr}$ and after replacement of particle-containing media with fresh media, further incubated for 1 day in order to see GFP expression by a fluorescence microscope (scale bar, $50 \mu \mathrm{m}$ ). 


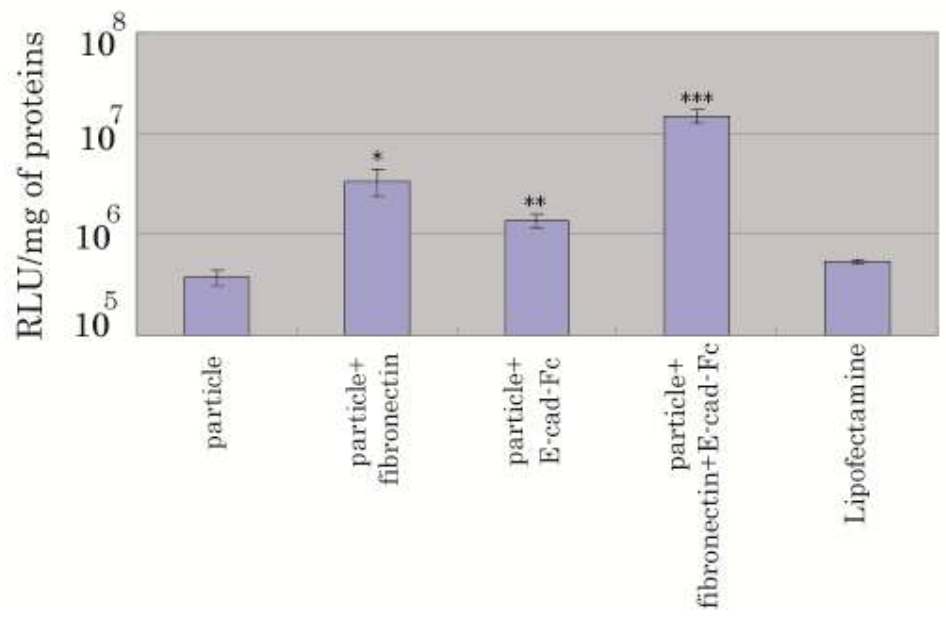

Figure 14. Comparison of luciferase expression for differentially formulated apatite particles and liposomes. Particles were prepared by addition of $3 \mu \mathrm{l}$ of $1 \mathrm{M} \mathrm{CaCl}_{2}, 2 \mu \mathrm{g}$ of luciferase plasmid DNA and $2 \mu \mathrm{g}$ of either fibronectin, E-cad-Fc or both to $1 \mathrm{ml}$ bicarbonate-buffered DMEM and incubation for $30 \mathrm{~min}$ at $37^{\circ} \mathrm{C}$. Embryonic stem cells were incubated with the generated particles for $4 \mathrm{hr}$ and after replacement of particle-containing media with fresh media, further incubated for 1 day in order to quantitate luciferase expression. Transfection efficiency was normalized after estimation of total proteins in cell lysate. Transfection by lipofectamine was performed according to the instructions provided by Invitrogen.

\subsection{DNA binding with differentially formulated cell adhesive protein-embedded particles}

Since direct mixing of DNA and cell-adhesive proteins in $\mathrm{Ca}^{2+}$ and $\mathrm{PO}_{4}{ }^{3-}$-containing medium prior to induction of particle formation by incubation at $37^{\circ} \mathrm{C}$ for $30 \mathrm{~min}$, could interfere with maximum DNA loading due to the competitive binding of the proteins to the growing crystals, we investigated DNA binding efficiency by first adding DNA to the particle-preparation medium prior to time-dependent addition of the proteins [22]. As shown in Fig. 15, in the direct mixing process (control), DNA binding is much higher for E-cadherin-Fc compared to fibronectin, indicating that E-cadherin-Fc facilitates DNA loading probably by accelerating particle growth because turbidity of particle suspension was higher for E-cadherinFc than for fibronectin (not shown). It is worth mentioning that only particles have also higher affinity towards DNA (almost 40\%) that the particles associated with fibronectin which showed lower turbidity than the particles (mentioned before), suggesting again that particle growth has a significant role in the observed DNA binding efficiency. When cell adhesive proteins were added after 5, 10 and 20 min from the start of incubation of DNA-containing particlepreparation medium, followed by incubation for an additional 25, 20 and 10 min respectively, DNA binding to the particles was enhanced to a significant extent for fibronectin, Ecadherin and fibronectin/E-cadherin-Fc compared to the control, suggesting than a competitive 
inhibition of DNA binding happens in the direct mixing procedure while delaying addition of the proteins to the growing crystals and DNA favors optimal DNA binding to the particles. Decreased DNA binding to the particles with which E-cadherin and fibronectin/E-cadherinFc were incubated for only $1 \mathrm{~min}$, could be due to the reduced growth of the particles for too long time absence of E-cadherin-Fc in particle-preparation medium.

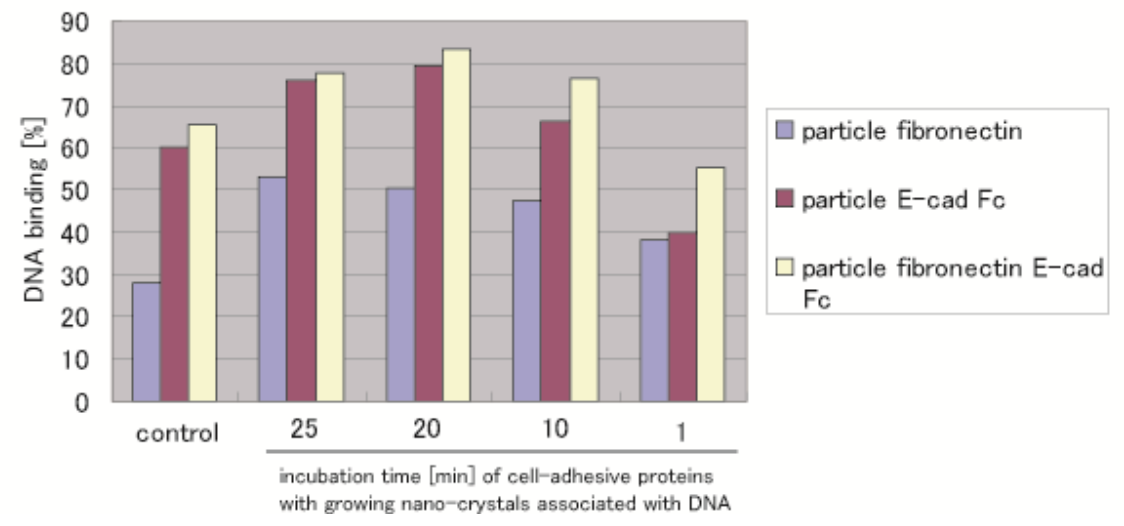

Figure 15. Binding affinities of DNA to differentially formulated cell adhesive protein-embedded particles. Particles in the control samples were prepared by addition of $3 \mu \mathrm{l}$ of $1 \mathrm{M} \mathrm{CaCl}_{2}, 2 \mu \mathrm{g}$ of luciferase plasmid DNA and $2 \mu \mathrm{g}$ of either fibronectin, E-cad-Fc or both to $1 \mathrm{ml}$ bicarbonate-buffered DMEM and incubation at $37^{\circ} \mathrm{C}$ for $30 \mathrm{~min}$. Formation of the particles in experimental samples was done by addition of fibronectin, E-cadherin-Fc or both after 5, 10, 20 and 29 min from the start of incubation of DNA-containing particle preparation medium, followed by incubation for an additional 25, 20, 10 and 1 min respectively. F9 cells were incubated with the generated particles for $4 \mathrm{hr}$ and after replacement of particle-containing media with fresh media, further incubated up to 1 day for quantitation of luciferase expression. Transfection efficiency was normalized after estimation of total proteins in cell lysate.

\subsection{Size determination for differentially formulated cell adhesive protein-embedded particles}

Particle growth kinetics is correlated to the size of the finally formed particles and excessive growth lead to big size particles being inefficient for intracellular DNA delivery [11]. Since E-cadherin-Fc favors particle growth by making bridges among the neighboring Ecadherin-anchored crystals [14], prolonged incubation together with DNA for generation of functional particles might lead to large complex particles. As shown in Fig. 16, fibronectin association maintained the average particle diameter close to $300 \mathrm{~nm}$ whereas E-cadherinFc or fibronectin/E-cadherin-Fc induced the particle growth with an average diameter of approximately $900 \mathrm{~nm}$. However, addition of E-cadherin-Fc or fibronectin/E-cadherin-F after 5, 10, 20 and $29 \mathrm{~min}$ from the start of incubation of DNA-containing particle-preparation medium, followed by incubation for an additional 25, 20, 10 and 1 min respectively, resulted in the particles of decreasing sizes with a minimum average value of approximately $300 \mathrm{~nm}$. On the other hand, time-dependent association of fibronectin having no role in 
particle growth induction, demonstrated no significant change in overall particle diameter, suggesting that particle growth is the size-determining factor for cell-adhesive proteinembedded particles.

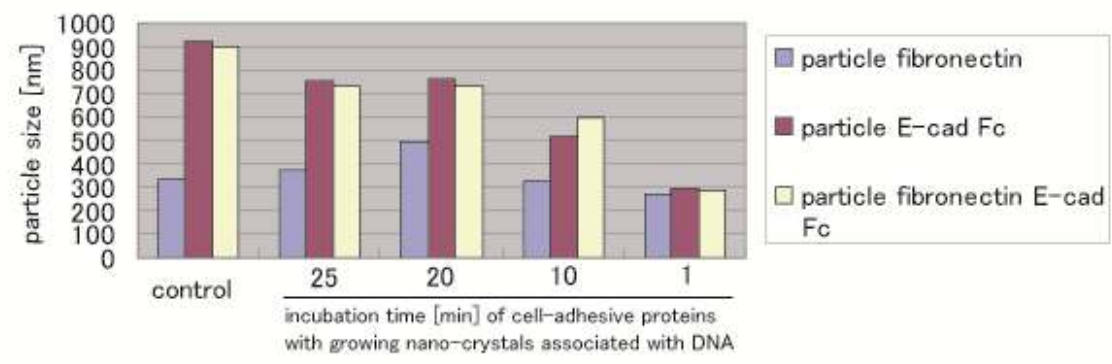

Figure 16. Estimation of sizes for differentially formulated cell adhesive protein-embedded particles. Following preparation of different particles as mentioned in the legend to Figure 4, dynamic light scattering (DLS) measurement was performed with a Super-dynamic Light Scattering Spectrophotometer.

\subsection{Cellular delivery of DNA in association with cell adhesive protein-embedded particles}

Both DNA binding to the particles and particle size contribute to the overall uptake of DNA by cells. As shown in Fig. 17, only particles were very inefficient in delivering propidium (PI)-labeled plasmid DNA into F9 cells whereas particles being associated with fibronectin or E-cadherin-Fc significantly increased cellular delivery of labeled DNA in a $4 \mathrm{hr}$ uptake study. Moreover, particles when complexed with both fibronectin and E-cadherin-Fc in direct mixing with DNA, synergistically accelerated delivery of PI-labeled DNA into the cells. Particles prepared by addition of fibronectin or fibronectin/E-cadherin-Fc after 5, 10 and $20 \mathrm{~min}$ from the start of incubation of labeled DNA-containing particle preparation medium and incubation for an additional 25, 20 and 10 min respectively, mediated increased cellular delivery of labeled DNA, indicating that transgene delivery is wellcontrolled by the sizes as well as the DNA-loading efficiency of cell adhesive proteinembedded particles. Reduced DNA uptake level for the small size particles with which cell-adhesive proteins were incubated for a very short time $(1 \mathrm{~min})$ could be accounted for their inefficient binding with the cell-recognition molecules. The reason for low DNA uptake for the particles to which only E-cadherin-Fc was adsorbed in a time-dependent manner, is still not clear and might be related to the serum instability of the complex particles at the time of transgene delivery. 


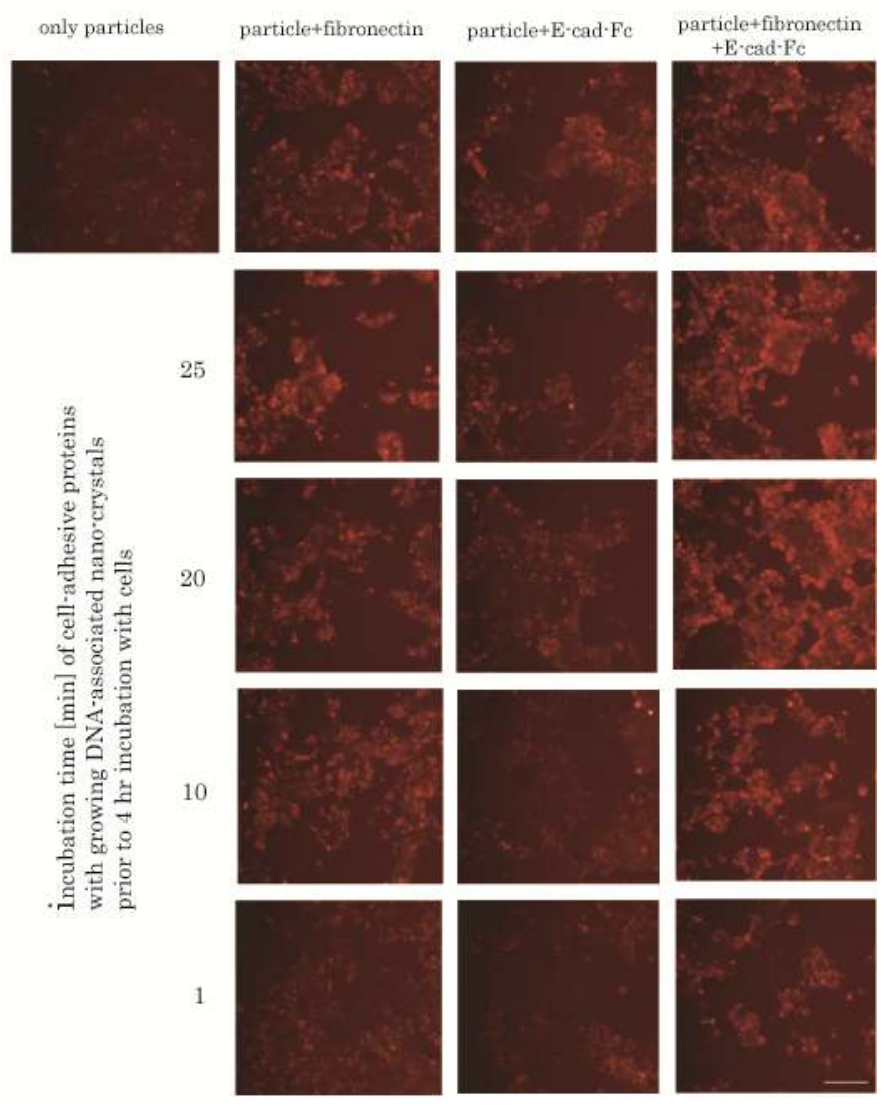

Figure 17. Differentially formulated cell adhesive protein-embedded particles for cellular delivery of DNA. Particles in the control samples were prepared by addition of $3 \mu \mathrm{l}$ of $1 \mathrm{M} \mathrm{CaCl}_{2}, 2 \mu \mathrm{g}$ of PI-labelled plasmid DNA and $2 \mu \mathrm{g}$ of either fibronectin, E-cad-Fc or both to $1 \mathrm{ml}$ bicarbonate-buffered DMEM and incubation at $37^{\circ} \mathrm{C}$ for $30 \mathrm{~min}$. Formation of the particles in experimental samples was done by addition of fibronectin, E-cadherin-Fc or both after 5, 10, 20 and 29 min from the start of incubation of DNA-containing particle preparation medium, followed by incubation for an additional 25, 20, 10 and 1 min respectively. F9 cells were incubated with the generated particles for 4 hr, washed with 5 mM EDTA in PBS and visualized by a fluorescence microscope (scale bar, $100 \mu \mathrm{m}$ ).

\subsection{Transfection efficiency achieved with cell adhesive protein-embedded particles}

Since transgene expression is the result of overcoming a number of barriers including entry into the cells, release from the particles and endosomes, and finally nuclear translocation [11], we checked whether accelerated DNA delivery owing to the improved DNA loading capacity and smaller sizes of fibronectin and E-cadherin-Fc-anchored carbonate apatite particles, contributed to the similar extent to final protein expression (Fig. 18). Quantitative luciferase expression demonstrated that particles generated by addition of fibronectin and 
fibronectin/E-cadherin-Fc after 5 min from the start of incubation of DNA-containing medium and incubation for an additional $25 \mathrm{~min}$, enhanced 2 and 3-fold higher transgene expression than the control samples prepared by direct mixing with DNA. This is a significant achievement considering the high expression level already achieved with control samples [15]. The decline in luciferase expression for other samples is consistent with the low efficiency of DNA delivery as described before.

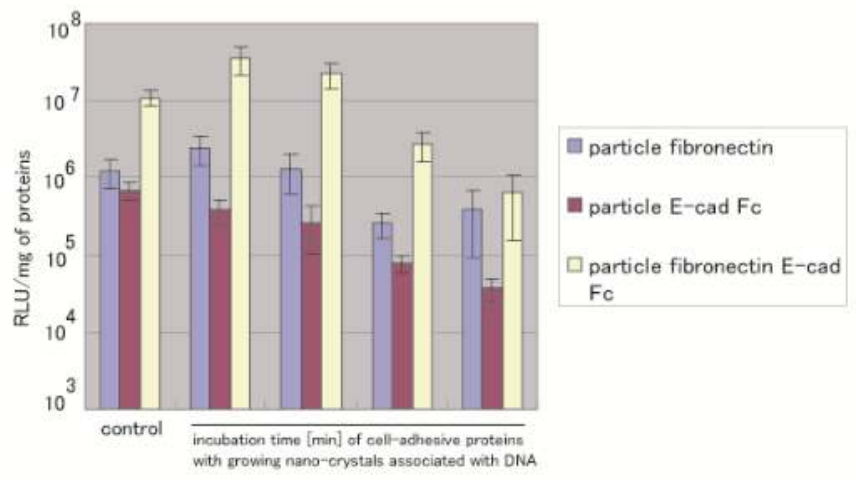

Figure 18. Intracellular expression of luciferase gene delivered by differentially formulated cell adhesive protein-embedded particles. Particles in the control samples were prepared by addition of $3 \mu \mathrm{l}$ of $1 \mathrm{M} \mathrm{CaCl}_{2}, 2 \mu \mathrm{g}$ of PI-labelled plasmid DNA and $2 \mu \mathrm{g}$ of either fibronectin, E-cad-Fc or both to $1 \mathrm{ml}$ bicarbonate-buffered DMEM and incubation at $37^{\circ} \mathrm{C}$ for $30 \mathrm{~min}$. Formation of the particles in experimental samples was done by addition of fibronectin, E-cadherinFc or both after 5, 10, 20 and 29 min from the start of incubation of DNA-containing particle preparation medium, followed by incubation for an additional 25, 20, 10 and 1 min respectively. F9 cells were incubated with the generated particles for $4 \mathrm{hr}$ and after replacement of particle-containing media with fresh media, further incubated up to 1 day in order to quantitate luciferase expression. Transfection efficiency was normalized after estimation of total proteins in cell lysate.

\subsection{Role of protein kinase $C$ on immobilized fibronectin and E-cad-Fc-mediated gene delivery}

Since protein kinase C (PKC) in "inside-out" signaling cascade enhances integrin affinity towards ECM proteins promoting cell adhesion and spreading [23, 24] and up regulates endocytosis and recycling of E-cadherin [21], we have investigated the effect of Phorbol 12-myristate 13-acetate (PMA), a specific activator of PKC on trans-gene delivery mediated by particle-immobilized fibronectin and E-cadherin-Fc. As shown in Fig. 19, while only carbonate apatite particles are very inefficient in transfecting F9 cells even in presence of increasing doses of PMA (0 to $100 \mathrm{nM}$ ), fibronectin- or E-cad-Fc-embedded particles showed significant increment in luciferase gene expression ( 2 to 10 times) depending on PMA concentrations. Surprisingly, particles when associated with both of the "cell adhesive molecules" remarkably enhanced trans-gene expression resulting in almost 8, 14, 20 
and 92-fold higher efficiency due to the presence of PMA at 1, 10, 50 and $100 \mathrm{nM}$ concentrations, respectively. Immobilization of either fibronectin or E-cad-Fc on the particles also showed a dramatic increment in transgene expression, indicating clearly that both of the transmembrane proteins integrin and E-cadherin are up-regulated in response to PKC activation to promote efficient internalization of the bio-functional particles across the plasma membrane (data not shown here) and subsequent expression of the particle-associated DNA in cytoplasm [27] (Fig 19).

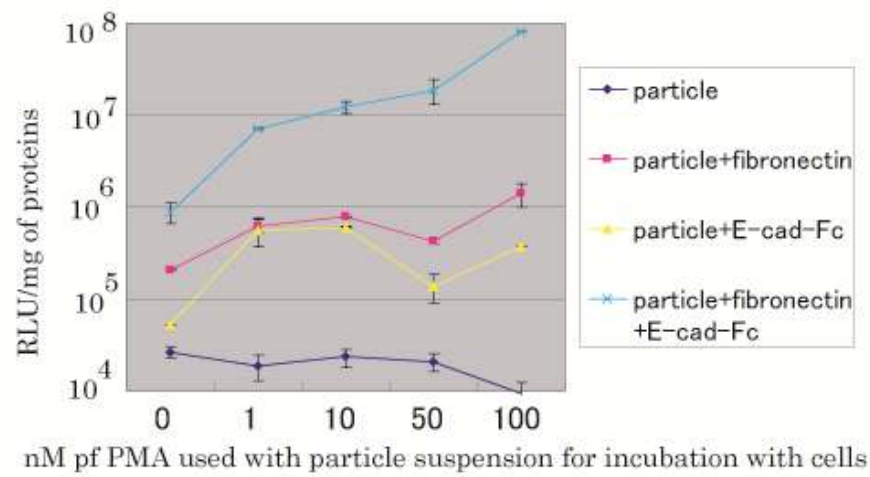

Figure 19. Effects of PMA on trans-gene expression mediated by fibronectin/E-cad-Fc-embedded-particles. Particles were prepared by addition of $3 \mu \mathrm{l}$ of $1 \mathrm{M} \mathrm{CaCl}_{2}, 2 \mu \mathrm{g}$ of luciferase plasmid DNA and $2 \mu \mathrm{g}$ of either fibronectin, E-cad-Fc or both to $1 \mathrm{ml}$ bicarbonate-buffered DMEM and incubation for $30 \mathrm{~min}$ at $37^{\circ} \mathrm{C}$. F9 cells were incubated with the generated particles in presence of increasingly high concentrations of PMA (o to $100 \mathrm{nM}$ ) for $1 \mathrm{hr}$ and after replacement of particle- and PMA-containing media with fresh media, further incubated for 1 day in order to quantitate luciferase expression.

\subsection{Transfection efficiency achieved in leukemia cells with cell adhesive protein- embedded particles}

T cell expresses on its membrane $\alpha 4 \beta 1$ and $\alpha 5 \beta 1$ integrins which can bind fibronectin during lymphocyte adhesion and migration from vascular compartment to the injured tissues [22]. Moreover, $\alpha_{\mathrm{E}} \beta 7$ integrin on some T cells can interact with epithelial E-cadherin for tissue-specific retention of lymphocytes [22]. We, therefore, aimed to functionalize the surface of DNA-associated nanocrystals with fibronectin and E-cadherin-Fc for transgene delivery through integrin-mediated endocytosis [22].

As shown in Fig. 20, luciferase expression in Jurkat cells was significantly low after delivery of luciferase gene-containing plasmid DNA with the help of carbonate apatite particles. A 3fold enhancement in transgene expression was observed following delivery with fibronectin-embedded particles. Transgene expression could be further increased to the level (up to 6 times) equivalent to that of lipofection with the particles complexed with both fibronectin and E-cadherin-Fc. Since lymphocytes posses 2 different types of integrins ( $\alpha 4 \beta 1$ and $\alpha 5 \beta 1$ ) 
being able to bind fibronectin [22], particles with electrostatically associated fibronectin could recognize any of the two receptors for efficient endocytosis in Jurkat cells leading to high transgene expression. However, particles with adsorbed E-cadherin-Fc reduced transfection efficiency below the level obtained with particles only, indicating that binding of Ecadherin-Fc probably neutralizes the positive charges of the particles as required for their subsequent interaction with anionic cell surface and additionally, E-cadherin-Fc on the particle surface might have low affinity interaction with the cell membrane integrin $\left(\alpha_{\mathrm{E}} \beta 7\right)$. On the other hand, the highest gene expression obtained with the particles complexed with both fibronectin and E-cadherin-Fc could be interpreted by the strong affinity of the composite particles towards the cell membrane due to the specific and synchronized recognition of the two different ligands on particle surface to their corresponding integrin receptors on plasma membrane, resulting in fast endocytosis of the particles along with DNA.

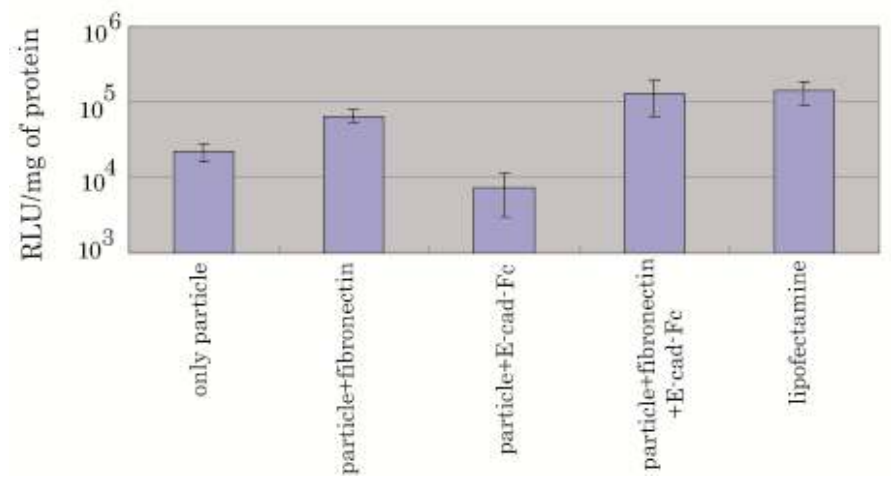

Figure 20. Comparison of luciferase expression among differentially formulated apatite particles. Particles were prepared by addition of $3 \mu \mathrm{l}$ of $1 \mathrm{M} \mathrm{CaCl}_{2}, 2 \mu \mathrm{g}$ of luciferase plasmid DNA and $2 \mu \mathrm{g}$ of either fibronectin, E-cad-Fc or both to $1 \mathrm{ml}$ bicarbonate-buffered DMEM and incubation for $30 \mathrm{~min}$ at $37^{\circ} \mathrm{C}$. Jurkat cells were incubated with the generated particles for 1 day followed by quantitation of luciferase expression. Transfection efficiency was normalized after estimation of total proteins in cell lysate. Transfection by lipofectamine was performed according to the instructions provided by Invitrogen. Reproducibility of the result was established by performing same the experiment in another day.

\section{Conclusions}

Stem cells possessing the inherent capability of transforming into many cell types, have been shown tremendous potential for cell-based therapies in regenerative medicine for neurological disease or injury [28], diabetes [29] and myocardial infarct [30]. The in vitro differentiated derivatives of stem cells are thought to be able to repair or replace damaged cells, tissues or organs. However, compared to embryonic stem cells, adult stem cells are likely more difficult to be implemented into useful therapies considering their limited pluripotency. Transgene delivery could be a powerful strategy for specific differentiation of embryonic stem 
cells since several transcription factors have been demonstrated to regulate stem cell differentiation to specific cell types of heart, pancreas, liver and neurons [31-36]. On the other hand, tumor cells such as leukemia and lymphoma cells are obvious and attractive targets for gene therapy. Gene transfer and expression for cytokine and immunomodulatory molecules in various kinds of tumor cells have been shown to mediate tumor regression and antimetastatic effects [37-40]. Moreover, genetically modified leukemia cells expressing costimulatory molecules or cytokines are likely to have significant therapeutic roles for patients with leukemia [41, 42].

Among the existing approaches for transgene delivery, viral systems suffer from their potential life-threatening effects of immunogenicity and carcinogenicity whereas non-viral ones, although safe, possess significant limitation in terms of efficacy [43]. Development of a safe as well as an efficient carrier is, therefore, an urgent requirement for effective implementation of the stem cells in regenerative medicine and the leukemia (or lymphocytes) in cancer treatment.

We have established a novel type of non-viral gene delivery systems based on $\mathrm{pH}$-sensitive inorganic nanoparticles and revealed an innovative strategy for surface-functionalization of these biodegradable nanoparticles through their ionic interactions with "cell-adhesive molecules". Moreover, the new approach has directly been applied for highly efficient delivery and expression of a trans-gene into "hard-to-transfect" embryonic stem cells- a success with tremendous future for stem-cell based therapeutic development. The involvement of E-cadherin and fibronectin in intercellular and extracellular interactions of cultured undifferentiated embryonic stem cells may exclude the possibility of stem cell differentiation following transfection with the new nano-apatite carriers associated with E-cad-Fc and fibronectin. More the same approach has successfully used to transfect the leukemia cells having potential application in cancer therapy.

\section{Acknowledgements}

This work has financially been supported by a research grant (Project ID 02-02-09-SF0013) of the Ministry of Science, Technology and Innovation (MOSTI), Malaysia.

\section{Author details}

\section{Ezharul Hoque Chowdhury*}

Address all correspondence to: md.ezharul.hoque@med.monash.edu.my

Jeffrey Cheah School of Medicine and Health Sciences, Faculty of Medicine, Nursing and Health Sciences, Monash University (Sunway Campus), Australia 


\section{References}

[1] Kopatz, I., Remy, J. S., \& Behr, J. P. (2004). A model for non-viral gene delivery: through syndecan adhesion molecules and powered by actin. Journal Gene Medicine, 6, 769-776.

[2] Wu, G. Y., \& Wu, C. H. (1997). Receptor-mediated in vitro gene transformation by a soluble DNA carrier system. Journal Biological Chemistry, 262, 4432-4439.

[3] Cotton, M., Längle-Rouault, F., Kirlappos, H., Wagner, E., Mechtler, K., Zenke, M., Beug, H., \& Birnstiel, M. L. (1990). Transferrin-polycation-mediated introduction of DNA into human leukemic cells: stimulation by agents that affect the survival of transfected DNA or modulate transferrin receptor levels. Proceedings of the National Academy of Sciences, 87, 4033-4037.

[4] Schaffer, D. V., \& Lauffenburger, D. A. (1998). Optimization of cell surface binding enhances efficiency and specificity of molecular conjugate gene delivery. Journal Biological Chemistry, 273, 28004-28009.

[5] Erbacher, P., Bousser, M. T., Raimond, J., Monsigny, M., Midoux, P., \& Roche, A. C. (1996). Gene transfer by DNA/glycosylated polylysine complexes into human blood monocyte-derived macrophages. Human Gene Therapy, 7, 721-729.

[6] Hoganson, D. K., Chandler, L. A., Fleurbaaij, G. A., Ying, W., Black, ME, Doukas, J., Pierce, G. F., Baird, A., \& Sosnowski, BA. (1998). Targeted delivery of DNA encoding cytotoxic proteins through high-affinity fibroblast growth factor receptors. Human Gene Therapy, 9, 2565-2575.

[7] Buschle, M., Cotton, M., Kirlappos, H., Mechtler, K., Schaffner, G., Zauner, W., \& Birnstiel, M. L. (1995). Receptor-mediated gene transfer into human T lymphocytes via binding of DNA/CD3 antibody particles to the CD3 T cell receptor complex. Human Gene Therapy, 6, 753-761.

[8] Erbacher, P., Remy, J. S., \& Behr, J. P. (1999). Gene transfer with synthetic virus-like particles via the integrin-mediated endocytosis pathway. Gene Therapy, 6, 138-145.

[9] Wang, S., Lee, R. J., Cauchon, G., Gorenstein, D. G., \& Low, P. S. (1995). Delivery of antisense oligodeoxyribonucleotides against the human epidermal growth factor receptor into cultured KB cells with liposomes conjugated to folate via polyethylene glycol. Proceedings of the National Academy of Sciences, 92, 3318-3322.

[10] Parkes, R. J., \& Hart, S. L. (2000). Adhesion molecules and gene transfer. Advanced Drug Delivery Reviews, 44, 135-152.

[11] Chowdhury, E. H. (2007). pH-sensitive nano-crystals of carbonate apatite for smart and cell-specific transgene delivery. Expert Opinion Drug Delivery, 4, 193-196.

[12] Chowdhury, E. H., Maruyama, A., Kano, A., Nagaoka, M., Kotaka, M., Hirose, S., Kunou, M., \& Akaike, A. (2006). pH-sensing nano-crystals of carbonate apatite: ef- 
fects on intracellular delivery and release of DNA for efficient expression into mammalian cells. Gene, 376, 87-94.

[13] Chowdhury, E. H., Kutsuzawa, K., \& Akaike, T. Designing Smart Nano-apatite Composites: The Emerging era of non-viral gene delivery. Gene Therapy and Molecular Biology, 9, 301-316.

[14] Kutsuzawa, K., Maruyama, K., Akiyama, Y., Akaike, T., \& Chowdhury, E. H. (2008). Efficient transfection of mouse embryonic stem cells with cell-adhesive protein-embedded inorganic nanocarrier. Analytical Biochemistry, 372, 122-124.

[15] Kutsuzawa, K., Chowdhury, E. H., Nagaoka, M., Maruyama, K., Akiyama, Y., \& Akaike, T. (2006). Surface functionalization of inorganic nano-crystals with fibronectin and E-cadherin chimera synergistically accelerates trans-gene delivery into embryonic stem cells. Biochemical and Biophysical Research Communications, 350, 514-520.

[16] Shirayoshi, Y., Okada, T. S., \& Takeichi, M. (1983). The calcium-dependent cell-cell adhesion system regulates inner cell mass formation and cell surface polarization in early mouse development. Cell, 35, 631-638.

[17] Oka, M., Tagoku, K., Russell, T. L., Nakano, Y., Hamazaki, T., Meyer, E. M., Yokota, T., \& Terada, N. (2002). CD9 is associated with leukemia inhibitory factor-mediated maintenance of embryonic stem cells. Molecular Biology of the Cell, 13, 1274-1281.

[18] Chowdhury, E. H., Zohra, F. T., Tada, S., Kitamura, C., \& Akaike, T. (2004). Fibronectin in collaboration with $\mathrm{Mg}^{2+}$ enhances transgene expression by calcium phosphate coprecipitates. Analytical Biochemistry, 335, 162-164.

[19] Chowdhury, E. H., Nagaoka, M., Ogiwara, K., Zohra, F. T., Kutsuzawa, K., Tada, S., Kitamura, C., \& Akaike, T. (2005). Integrin-supported fast rate intracellular delivery of plasmid DNA by extracellular matrix protein embedded calcium phosphate complexes. Biochemistry, 44, 12273-12278.

[20] Overduin, M., Harvey, T. S., Bagby, S., Tong, K. I., Yau, P., Takeichi, M., \& Ikura, M. (1995). Solution structure of the epithelial cadherin domain responsible for selective cell adhesion. Science, 267, 386-389.

[21] Le Joseph, T. L., Yap, S. R., , A. S., \& Stow, J. L. (2002). Protein kinase C regulates endocytosis and recycling of E-cadherin. American Journal of Physiology- Cell Physiology, 283, C489-C499.

[22] Kutsuzawa, K., Maruyama, K., Akiyama, Y., Akaike, T., \& Chowdhury, E. H. (2008). The influence of the cell-adhesive proteins E-cadherin and fibronectin embedded in carbonate-apatite DNA carrier on transgene delivery and expression in a mouse embryonic stem cell line. Biomaterials, 29, 370-376.

[23] Kolanus, W., \& Seed, B. (1997). Integrins and inside-out signal transduction: converging signals from PKC and PIP3. Current Opinion in Cell Biology, 9, 725-731. 
[24] Besson, A., Wilson, T. L., \& Yong, V. W. (2002). The anchoring protein RACK1 links protein kinase Cepsilon to integrin beta chains. Requirements for adhesion and motility. Journal Biological Chemistry, 277, 22073-22084.

[25] Stephens, L. E., Sonne, J. E., Fitzgerald, M. L., \& Damsky, C. H. (1993). Targeted deletion of beta 1 integrins in F9 embryonal carcinoma cells affects morphological differentiation but not tissue-specific gene expression. Journal of Cell Biology, 123, 1607-1620.

[26] Maeno, Y., Moroi, S., Nagashima, H., Noda, T., Shiozaki, H., Monden, M., Tsukita, S., \& Nagafuchi, A. (1999). alpha-catenin-deficient F9 cells differentiate into signet ring cells. American Journal of Pathology, 154, 1323-1328.

[27] Kutsuzawa, K., Maruyama, K., Akiyama, Y., Akaike, T., \& Chowdhury, E. H. (2007). Protein kinase $\mathrm{C}$ activation enhances transfection efficacy of cell-adhesive proteinanchored carbonate apatite nanocrystals. Analytical Biochemistry, 37, 116-117.

[28] Webber, D. J., \& Minger, S. L. (2004). Therapeutic potential of stem cells in central nervous system regeneration. Current Opinion in Investigational Drugs, 5, 714-719.

[29] Hussain, M. A., \& Theise, N. D. (2004). Stem-cell therapy for diabetes mellitus. Lancet, 364, 203-205.

[30] Mathur, A., \& Martin, J. F. (2004). Stem cells and repair of the heart. Lancet, 364, 183-192.

[31] Duncan, S. A., Navas, MA, Dufort, D., Rossant, J., \& Stoffel, M. (1998). Regulation of a transcription factor network required for differentiation and metabolism. Science, 281, 692-695.

[32] Li, J., Ning, G., \& Duncan, S. A. (2000). Mammalian hepatocyte differentiation requires the transcription factor HNF-4alpha. Genes and Development, 14, 464-474.

[33] Ishizaka, S., Shiroi, A., Kanda, S., Yoshikawa, M., Tsujinoue, H., Kuriyama, S., Hasuma, T., Nakatani, K., \& Takahashi, K. (2002). Development of hepatocytes from ES cells after transfection with the HNF-3beta gene. FASEB Journal, 16, 1444-1446.

[34] Dohrmann, C., Gruss, P., \& Lemaire, L. (2000). Pax genes and the differentiation of hormone-producing endocrine cells in the pancreas. Mechanisms of Development, 92, 47-54.

[35] Kim, S. K., \& Hebrok, M. (2001). Intercellular signals regulating pancreas development and function. Genes and Development, 15, 111-127.

[36] Xian, H. Q., \& Gottlieb, D. I. (2001). Peering into early neurogenesis with embryonic stem cells. Trends in Neurosciences, 24, 685-686.

[37] Adams, S. W., \& Emerson, S. G. (1998). Gene therapy for leukemia and lymphoma. Hematology/Oncology Clinics of North America, 12(3), 631-48. 
[38] Schakowski, F., Buttgereit, P., Mazur, M., Märten, A., Schöttker, B., Gorschlüter, M., \& Schmidt-Wolf, I. G. (2004). Novel non-viral method for transfection of primary leukemia cells and cell lines. Genetic Vaccines and Therapy, 2(1), 1.

[39] Szeps, M., Erickson, S., Gruber, A., Castro, J., Einhorn, S., \& Grandér, D. (2003). Effects of interferon-alpha on cell cycle regulatory proteins in leukemic cells. Leukemia and Lymphoma, 44(6), 1019-25.

[40] Finke, S., Trojaneck, B., Lefterova, P., Csipai, M., Wagner, E., Kircheis, R., Neubauer, A., Huhn, D., Wittig, B., \& Schmidt-Wolf, I. G. (1998). Increase of proliferation rate and enhancement of antitumor cytotoxicity of expanded human CD3+ CD56+ immunologic effector cells by receptor-mediated transfection with the interleukin-7 gene. Gene Therapy, 5(1), 31-9.

[41] Notter, M., Willinger, T., Erben, U., \& Thiel, E. (2001). Targeting of a B7-1 (CD80) immunoglobulin $\mathrm{G}$ fusion protein to acute myeloid leukemia blasts increases their costimulatory activity for autologous remission T cells. Blood, 97(10), 3138-45.

[42] Kato, K., Cantwell, MJ, Sharma, S., \& Kipps, T. J. (1998). Gene transfer of CD40-ligand induces autologous immune recognition of chronic lymphocytic leukemia $\mathrm{B}$ cells. Journal of Clinical Investigation, 101(5), 1133-1141.

[43] Chowdhury, E. H., \& Akaike, T. (2005). Bio-functional inorganic materials: an attractive branch of gene-based nano-medicine delivery for 21st century. Current Gene Therapy, 5, 669-676. 